\title{
Huertas domésticas y políticas de agricultura urbana: ¿desde el autoconsumo hasta el mercado?
}

\author{
Kitchen-gardens and Urban agriculture politics: from self-consumption to \\ the market?
}

\author{
Daniel Velandia-Díaz ${ }^{1}$
}

$E^{n}$ la actualidad existen en Colombia muchos proyectos comunitarios de agricultura orgánica y urbana; particularmente, conozco algunos localizados en la ciudad de Bogotá desde el año 2004. En el año 2008 desarrollé una investigación independiente sobre la apropiación y la exclusión de conocimientos científicos en algunas experiencias de agricultura urbana. Esta investigación tuvo como resultado principal un documento de trabajo que esbozó las tensiones existentes entre las "comunidades" y las "instituciones" (Velandia-Díaz, 2008). En esta carta quiero hacer énfasis en la disyuntiva existente entre el autoconsumo y el mercado.

En Bogotá, a comienzos del siglo XXI, se presentaron políticas institucionales para fortalecer aspectos sociales tales como la agricultura urbana, la alimentación saludable y la integración comunitaria. Muchas de estas políticas estuvieron asociadas a la preocupación por la inclusión social y fueron dirigidas por las alcaldías de la ciudad. En los planes de gobierno: "Bogotá Sin Indiferencia” (2004-2007), "Bogotá Positiva" (2008-2011) y "Bogotá Humana" (2012-2015), se adelantaron sendos procesos de intervención para conformar redes de agricultura urbana en algunas localidades de la ciudad. Estas intervenciones promovieron el reconocimiento de experiencias comunitarias previas, tanto como apoyaron la emergencia de nuevas iniciativas en el contexto de la agricultura urbana.

De la misma forma, muchos procesos alrededor de la agricultura en Bogotá tuvieron influencia de agencias y Organizaciones No Gubernamentales (ONG), algunas nacionales (v.g. Fundación Colombia Multicultural 2005-2010) y otras con origen en otros países (v.g. Agencia Japonesa de Cooperación Internacional - JICA). La mayoría de ellas brindaron asesoría técnica y/o entregaron suministros para que las comunidades pudiesen emprender procesos propios de agricultura urbana. De hecho, en algunos casos se presentó la convergencia entre estas organizaciones y las políticas de los gobiernos de la ciudad. No obstante, la principal institución gubernamental relacionada con la agricultura urbana, desde hace años y hasta ahora, es el Jardín Botánico de Bogotá José Celestino Mutis.

El Jardín Botánico ha desarrollado un proceso de investigación y aplicación de la agricultura urbana. El escenario más popular de este proceso es la exhibición permanente de cultivos al interior de las

1. Doctor en Antropología. Profesor Universidad del Magdalena. Colombia. Correo electrónico: dvelandia@unimagdalena.edu.co / dvelandiad@unal. edu.co ORCID ID: 0000-0001-5523-8479. 
instalaciones del Jardín. Allí se exhiben diferentes modalidades de siembra, técnicas de compostaje y una importante diversidad de plantas (ver www. jbb.gov.co). Además de esto, el Jardín lleva a cabo un proceso permanente de conservación de semillas y de producción de abonos orgánicos, tanto como ha realizado ferias para el intercambio y la venta de hortalizas, frutas, plantas medicinales y plantas aromáticas. Si bien estas actividades son públicas y cualquier persona interesada puede conocerlas con una visita a las instalaciones, hay otras actividades especializadas para el apoyo a los agricultores y las agricultoras urbanas.

En términos generales, durante los periodos de gobierno señalados, la interacción entre el Jardín Botánico y las personas interesadas en la agricultura tuvo como finalidad crear o fortale-cer huertas, iniciativas o procesos comunitarios. De una parte, las personas o los grupos aportaron interés y esfuerzo propio $y$, de otra parte, el Jardín ofreció apoyo con recursos materiales y asesores especializados. Desde el comienzo de esta relación apareció el asunto determinante: los procesos de agricultura urbana requerían la existencia de espacios físicos para ser desarrollados. Por esta razón, el Jardín, a través de sus asesores, realizó un reconocimiento y/o visitó los lugares donde se encontraban los agricultores y agricultoras y, después de esto, dio comienzo al proceso específico de establecimiento o mejoramiento de las huertas o la iniciativa.

De esta forma, el reconocimiento de las condiciones locales preexistentes permitió una intervención específica para cada iniciativa de agricultura urbana, especialmente porque hay procesos bien distintos que van desde el cultivo mismo hasta la elaboración de fertilizantes biopreparados. En los años 2008 y 2015 conocí huertas de la "Red de Agricultura Urbana de la Localidad de Suba" que vivieron tanto el reconocimiento como la planeación. En cada uno de esos años estuve en varios procesos similares que consistieron en la elaboración de un plan de trabajo que incorporó actividades, responsabilidades y resultados para el periodo de un año. En la formulación de estos planes se definieron asuntos como las especies y la cantidad de se-millas, las herramientas, la cantidad y las características de los abonos que el Jardín entregaría a los grupos, así como la mejora de los espacios físicos y la recolección de agua. De la misma forma, se definieron las jornadas de trabajo colectivo para cultivar y aprender a realizar diferentes actividades en las huertas.

Mis actividades en la Red han sido diversas, desde el aprendizaje de las técnicas de cultivo, pasando por el intercambio de experiencias con varios actores de la Red, hasta la vinculación a proyectos de inclusión social dirigidos por la Alcaldía; además, la Red se ha transformado puesto que los actores participantes cambian con el tiempo. Con esta experiencia logré registrar que un conjunto mayoritario de las personas beneficiadas deseaba incrementar la producción orgánica de hortalizas, tubérculos, frutas, abonos, plaguicidas, plantas medicinales y aromáticas con fines comerciales. Empero, otro conjunto importante de las personas deseaba, también, mejorar la producción y adquirir conocimientos nuevos con el fin principal de mejorar su calidad de vida y la alimentación al interior del hogar.

Por su parte, la asesoría técnica institucional en agricultura urbana buscó, entre otros objetivos y en la mayoría de los casos, incrementar la cantidad de la producción. Esto también significó que los grupos, huertas o iniciativas de la Red debían elegir los productos que querrían elaborar en mayor cantidad. Al parecer, este enfoque no tendría ninguna objeción y, de hecho, en alguna medida, todos los integrantes de la Red mejoraron sus experiencias y se fortalecieron con el apoyo institucional. Sin embargo, es necesario preguntarse cómo se relaciona la idea de aumentar la producción con las prácticas locales de cultivo para el autoconsumo. 
Específicamente, quienes tenían huertas propias e historias de producción previa, tenían también algunas metas que querían mantener a pesar del apoyo del Jardín Botánico. Es decir, no desea-ban que sus huertas se transformasen en pro-veedoras de otros consumidores: esto significaría reducir el consumo propio. De esta forma, se podría decir que se presentaron dos intencionalidades diferentes: (1) enfocar la producción en dos o tres especies de hortalizas, frutas o productos orgánicos para garantizar la producción regular y la comercialización en el futuro o (2) cultivar sobre la base del policultivo y la rotación permanente de especies para el autoconsumo, con técnicas como, por ejemplo, cambiar las especies de acuerdo con el uso y el agotamiento de los nutrientes de la tierra en cada cosecha.

Los asesores especializados del Jardín Botánico fueron conscientes de estas dos formas de concebir la agricultura. Y quizás por ello las iniciativas de agricultura no siempre han sido evaluadas sobre la base de la producción dirigida al mercado. En los procesos de agricultura urbana se da mayor relevancia al fomento de las relaciones comunitarias y al mejoramiento de las condiciones medioambientales para la ciudad. En mi experiencia, pude conocer cómo el apoyo al proceso de las huertas de la Red propició el mejoramiento de las condiciones de cultivo, de cosecha, de consumo familiar, de intercambio de productos al interior de la Red y de calidad de vida de las personas involucradas en la huerta.

Así, es posible señalar que la producción de alimentos no debería estar atada a la comercialización. Muchas políticas de agricultura urbana (Resources Urban Agriculture Found 2000), a pesar de contemplar metas "sociales" de forma implícita o dentro de los procesos de apoyo a los grupos locales, tienden a considerar la comercialización como el mejor escenario para el desarrollo de una huerta y los grupos que la sostienen. Sin embargo, considero que las políticas públicas en este sector podrían tener un enfoque dirigido a garantizar la existencia y el mantenimiento de "huertas domésticas" en el tiempo. De esta forma, los grupos de trabajo de las huertas o de las iniciativas podrán, si lo desean, tomar la decisión de incorporarse al mercado o no, a razón de las capacidades propias de producción de excedentes.

El mercado, que parecería ser una solución para las familias productoras, no debería ser el objetivo de las políticas de agricultura urbana. Mejor bien, se hace necesario el fortalecimiento de las prácticas de producción para el autoconsumo en amplios sectores de la población; por supuesto, a través de políticas públicas y alianzas con organizaciones sociales. Finalmente, no está de más señalar que la producción y la distribución de alimentos son asuntos que cada día toman mayor importancia pública y se hacen visibles las actividades de los sectores industriales. Alrededor de este asunto gravitan varias dimensiones de la agenda del siglo XXI, entre ellas: la reducción de las hambrunas y la pobreza, el mejoramiento de la calidad de vida, el consumo de alimentos saludables, el acceso a alimentos inocuos, las garantías de la producción en los países con "vocación" agrícola, el calentamiento global, la sostenibilidad medioambiental de los ecosistemas, las políticas de inclusión social, el reconocimiento de las actividades de las mujeres en la producción de alimentos y, por supuesto, la conservación y protección del agua.

\section{Referencias bibliográficas}

Velandia-Díaz, D. (2008). Apropiación y exclusión de la ciencia en agricultura urbana en Bogotá. Rio de Janeiro. Brasil. Documento de trabajo. Recuperado de www.necso.ufrj.br/esocite2008/ trabalhos/35741.doc

Resources Urban Agriculture Found (2000). Urban Agriculture Magazine 1(1). Recuperado de www. ruaf.org/ua-magazine-no-1-maiden-issue 